\title{
The UK Higher Education Senior Management Survey: a statactivist response to managerialist governance ${ }^{1}$
}

\author{
AUTHORS \\ Mark Erickson (corresponding author) \\ Reader in Sociology \\ School of Applied Social Science \\ University of Brighton \\ @drmarkerickson \\ m.erickson@brighton.ac.uk \\ ORCID: (ittps://orcid.org/0000-0001-6138-0412 \\ Paul Hanna \\ Senior Lecturer in Clinical Psychology \\ University of Surrey \\ Carl Walker \\ Reader in Psychology \\ School of Applied Social Science \\ University of Brighton
}

${ }^{1}$ An earlier version of this paper was presented at the 2018 WES Conference, Belfast 


\section{Disclosure statement}

No potential conflict of interest was reported by any of the authors.

\section{Author biographies}

\section{Mark Erickson}

Dr Mark Erickson is Reader in Sociology and Director of Postgraduate Studies at the University of Brighton. He is a sociologist with research interests in sociology of work and employment, sociology of science and technology, social theory and social research methods and methodology. His most recent book is Science, culture and society: understanding science in the $21^{\text {st }}$ century (Polity 2016).

\section{Paul Hanna}

Dr Paul Hanna is a Senior Lecturer in Clinical Psychology at the University of Surrey. Paul joined the University of Surrey in 2014 and since then has had appointments as Lecturer and Senior Lecturer in Sustainable Tourism, Deputy Chair of the University Ethics Committee, Post Graduate Research Director (SHTM), and Deputy Director of the Sustainability and Wellbeing Research Group (SHTM). Dr Hanna is an experienced consultant in both the public and private sectors and has extensive teaching and research experience. He has published extensively and has co-authored a recent book advancing knowledge and practice in Community Psychology (Walker C, Hart A, Hanna P (2017) Building a New Community Psychology of Mental Health: Spaces, Places, People and Activities, Palgrave Macmillan)

Carl Walker

Dr Carl Walker is a community psychologist from the University of Brighton and course leader in the MA Community Psychology. He is on the British Psychological Society National Community Psychology section committee. Recently he co-founded the national group 'Psychologists against Austerity' and his recent research involves action research projects on wellbeing drawing on statactivist techniques. Carl's main research interests include exploring the relations between debt, inequality and mental health and the use of community initiatives to work toward addressing mental health needs. He has used a range of social science methodologies to engage in collaborative, multi-stakeholder evaluations in the fields of health, mental health and wellbeing, disability, care and debt. In recent years he has established evaluation partnerships with a range of local groups including Local Authority, NHS and VCS organisations, including Community Works, MAS, The Richmond Fellowship, Amaze, Mindout and Mind in Brighton in Hove. 


\begin{abstract}
In this paper we present results from an extensive survey of United Kingdom (UK) university academics investigating satisfaction with senior managers and university governance: the Senior Management Survey (SMS). 5,888 academic staff across the United Kingdom Higher Education (HE) sector completed the survey, and results were used to construct a league table of staff satisfaction with management. This table is a stark indictment of the current state of the UK HE sector, showing a mean satisfaction score of $10.54 \%$. The SMS also collected qualitative data, and we extend the league table's insights using this data. Thematic analysis revealed seven major themes: the dominance and brutality of metrics; excessive workload; governance and accountability; perpetual change; vanity projects; the silenced academic; work and mental health. We conclude with a discussion of how this statactivist research can be used to bring about change in management and governance of UK $\mathrm{HE}$.
\end{abstract}

\title{
Keywords
}

Higher education, higher education management, academic labour process, statactivism, mental health, staff satisfaction

\section{Introduction}

Universities occupy a curious position in United Kingdom (UK) society; both of the state and separate from it, public institutions yet private enterprises, sites of learning and change but also places of tradition and ritual. We tell ourselves a mythical story of the university in our society; that it has a tradition dating back centuries, that it transformed itself into a modern, cutting edge knowledge generating institution, that it is a site of academic freedom and creative expression for students (Wallerstein 2006; Docherty 2015). Although some aspects of the story are mythic, many commentators identify a stated purpose that is shared across universities in the UK: universities do generate knowledge, do avow to promote academic freedom and they do profess to promote creativity in a community of scholars (Barnett 2003; Collini 2012; Docherty 2015; Smyth 2017). Indeed, the idea of a university as a community of scholars is still widely held in UK Higher Education (HE) (Docherty 2015: 23), and those who consider themselves to be members of such a community of scholars will cleave to the purpose of the university. 
However, the purpose of a university education has recently shifted from something concerned with individual development, critical thinking, and for broader societal benefits, to an understanding of a university education being assessed as worthwhile on the simple equation of degree cost against postgraduate employability (Fotiadou, 2018). In addition, it has become increasingly clear in recent years that universities are not simply selfmanaged communities of scholars, as our mythic history suggests, but are riven by a very deep division between senior managers in UK HE and academic staff (Barnett 2003; Collini 2012; Docherty 2015). This division, it can be argued, has always existed, even in medieval times, but it is clear from a review of recent writings on universities in the UK (e.g. Nash, 2019), and also from the survey results presented here, that institutional changes at a local level, and changes to UK HE at a national level, have deepened and widened this division very considerably.

In this paper we will focus on this division between senior managers and academic staff in UK HE institutions by investigating academic staff and their perceptions of senior managers in their institution. Using a 'statactivist' approach we designed and deployed a research instrument to appraise universities' senior managers performance in a HE system that has become increasingly characterised by its managerial audit culture. Rather than an operational survey that investigates staff 'engagement' or measures individual or collective performance against KPIs, this research focuses on HE staff members' perception of their working conditions, managerial practices and wellbeing. Here we contribute to the growing body of literature by offering an account of our context-dependent research which responds to, and critically engages with, the audit culture and new management practices of UK HE. For this reason, we will start with a review of recent literature to help contextualise the current state of UK HE.

\section{The current state of UK HE}

Recent literature documenting the current state of UK HE appears to point to a sector beset by a range of disparate but related issues. Just a cursory glance at some book titles give a flavour of what is happening in UK 
HE: The Assault on Universities (Bailey and Freeman 2011), Universities at War (Docherty 2015), The Toxic University (Smyth 2017, Zombie University (Murphy 2017) all highlight dramatic, even cataclysmic change and dire possible futures for the sector. Gill (2014) describes an increasing reliance upon corporate management techniques, the expansion of student numbers without an associated expansion of staff, workforce casualisation, increasingly unmanageable workloads and a proliferation of audit regimes oriented toward problematic notions of accountability as central to recent changes in the sector. Outside of HE a sense of disinterest and bewilderment is matched by a growing and pervasive sense of crisis and forms of exploitation within (Gill, 2014).

While some have critiqued the concept of neoliberalism as vague and conceptually overloaded (Downs, 2017), nonetheless it has retained a central position in academic accounts that attempt to make sense of the changing nature of the sector. Olssen and Peters (2005) and Edmond (2017) among others invoke the spectre of neoliberalism as a polity whose hard managerialism systematically deconstructs the space through which professional autonomy is exercised. This is achieved via the imposition of targets, performance criteria and homogenised systems for assessing research and teaching performance. Whether or not the 'neoliberal university' has sufficient analytic purchase beyond its status as a well-worn trope for the conspiracy of global capitalism (Downs, 2017) remains to be seen. However, it is clear that a radical project, grounded in particular ideas about public services and education, has been mobilised in UK HE in recent years.

The emergence of a neoliberal project inside UK HE coincided with the dramatic expansion of the UK HE sector in the early 1990s, when polytechnics were granted university status, coupled with the Labour government's aspiration for $50 \%$ of school leavers to go on to Higher Education. The number of HE providers doubled at a stroke in 1992, and there are now $160 \mathrm{HE}$ providers in the UK. In the period 1994 to 2017 the number of university students rose from $1,231,988$ to $1,766,285^{2}$. The Higher

\footnotetext{
2 1994-5 HESA figures 946919 FT UG and 285069 PT UG; 2016-17 1766285 FT and PT UG Source https://www.hesa.ac.uk/data-andanalysis/students/whos-in-he (accessed 20/05/19)
} 
Education Initial Participation Rate (HEIPR) for 20016-17 was $49.8 \%^{3}$.

The expansion of UK HE from 1992 coincided with the introduction of a significant performance measure, the Research Assessment Exercise (RAE). Now formally called the Research Excellence Framework (REF) the REF represents a formal and external assessment of the quality and impact of academic's research, largely through peer grading of publications ${ }^{4}$. The RAE, and now REF, can be seen as the first element of an ever-expanding performance audit, evaluation and management culture in UK universities.

\section{The audit mess of UK Higher Education}

Academics are estimated to be one of the most surveilled groups in history. Gill (2014) suggests that an academic can now be ranked on more than 100 different scales and indices that measure their value. These include what Burrows (2012) refers to as 'metric assemblages' (such as the REF and the Teaching Excellent Framework (TEF)) which take on a life of their own and become autonomous actors in the academic world, generating funding, damaging reputations, singling people out for redundancy and closing down courses.

Academic audit has been described as:

'an effortful collective outcome of an increasingly centralised and elaborated apparatus which becomes intertwined with a range of other organisational phenomena, shaping organisational perception, governance and strategic mobilisation' (Power 2015: 50)

\footnotetext{
${ }^{3}$ Source: https://www.gov.uk/government/statistics/participation-rates-inhigher-education-2006-to-2017 (accessed 200519)

'Academic communities' opposition to metric-based assessment regimes is not confined to the UK, or to this sort of 'research selectivity' exercise. The trend towards metric-based evaluation of research quality, and with it the 'quality' of those producing the research is, arguably, endemic across academia and across the globe. Opposition to this trend is manifested in local struggles against the inclusion of impact factor and citation scores in promotion evaluation procedures to national campaigns of opposition to exercises such as the REF in the UK, to international campaigns for the responsible use of research metrics, with the DORA campaign the most well known (https://sfdora.org/).
} 
These measurement infrastructures are mobilised to translate ambiguous policy objects like 'impact' and 'teaching quality' into routines capable of reproducing themselves. Indeed, such regimes can be profitable, with a high quality $4^{*}$ impact case study worth nearly the equivalent of four high quality academic papers, approximately $£ 120,000$ (Power, 2015).

Power (2000) describes how New Performance Management techniques have contributed to an 'audit explosion' across the public services with untested and uncritically implemented regulating systems applied to discipline and control doctors, teachers, university lecturers and other professionals. This flood of social measures that Power describes as 'quantifiable bureaucratic audits' have been justified as the necessary tools to ensure accountability, transparency and efficiency (Power 2000; Espeland and Saunder, 2007).

This explosion in audit culture has led to a dramatic rise in the amount of raw data available to university managers. Finn (2015) suggests that data that is wedded to rationalist performance logics allows the emergence of sensibilities of progress whereby complex social environments are made 'machine readable'. Indeed, the substantial justification for this data proliferation has been a perceived need to generate accountability, raise standards and increase consumer choice in a post-public HE arena. Here, accountability refers to a process of holding actors responsible for their actions and by consensus it involves both answerability and enforceability (Gaventa and McGee, 2013). However, while absorbing specific accountability recipes may be crucial for political and managerialist regimes to legitimise behaviour, they do not necessarily bear positively on either standards or democratic answerability (Gulbrandsen, 2008). Instead, audit cultures tend to construct a vocabulary of knowledge that legitimises managerial power at the expense of more traditional and collegial versions of the University (Craig et al 2014).

Such audits, rankings and league tables have been critiqued for giving authority to certain kinds of knowing and judging that decontextualizes and simplifies that which it seeks to measure, producing forms of knowledge that discourage individuals from noticing how inevitably generative such audit quantifications are (Espeland and Saunder, 2007). These depersonalised but 
highly portable numbers have allowed the proliferation of new spaces of calculation and new visibilities within which people internal and external to the sector can understand 'worth' and 'quality' (Ball, 2012).

In such regimes of performativity, experience is nothing and productivity is everything - an ever intensifying upward spiral of standards where last year's efforts are a benchmark for improvement (Ball 2012). There is little evidence that this metrics explosion in HE improves educational performance, with the REF having been described as 'hallucinatorily wasteful' (Gill, 2009). Moreover, the increased 'gaming' of the metrics, the utilitarian model of knowledge production that emerges (Ridley, 2017) and the increasing desensitisation of academics to their own objectification (Rudd and Goodson, 2017) has been argued as grounds for approaching these metric assemblages with the most profound care (Bal et al 2014).

Finn (2015) counsels scholars of HE to attune themselves to the 'affective atmospheres' (p4) of data collection regimens in order to understand the cultures of education that emerge through contemporary data proliferation. Ball (2012) has suggested that the rise of the audit is as much about the cultural and economic authority granted to those who call themselves auditors as it is about authentic accountability for public spending. Indeed, many have pointed the finger at this audit culture as the driving force behind the significant increases in volume of teaching, marking and research outputs in recent years (Martell, 2017).

A question of value concerns the subjects, and indeed, subjectivities that routinely emerge from these sets of practices. Metrics perform a powerful productive role in the social world by vindicating, limiting, cajoling, legitimising and justifying (Beer, 2016, Smyth 2017) where despite feeling neutral and objective, they manifestly participate in 'making people up' (Hacking 2002), changing their behaviours and developing expectations to adapt to the systems of measurement that they live within (Espeland and Saunder, 2007). Facilitated by a suffocating array of audit assemblages (Spooner, 2017), and ignited by an imposed 'pedagogy of debt' (Neary and Winn, 2017, p3) it has been suggested that we are witnessing a foregrounding of one instrumental purpose (skills and employment) over others (education for love, social 
benefit) (Downs, 2017) whereby cultures of audit and measurement are grotesquely distorting the very activities that they seek to scrutinise.

\section{Managerial governance}

Even if they were so inclined, the governing bodies of UK HE institutions would have great difficulty in challenging university executives. This is partly due to government bodies largely consisting of 'amateurs' unfamiliar with the complex and rapidly changing contours of UK HE operations, finance and core business (Ridley, 2017). The 1992 Education Reform Act transferred ownership of the old polytechnics from elected local councils to governmentapproved governing bodies often with little operational knowledge of HE (Rustin, 2016). Senior management teams now appoint self-selecting and self-reproducing boards of governors which allow them to exercise largely unlimited powers that are endorsed by governing boards, usually after faux exercises in consultation (Holmwood et al 2016). Ridley (2017) suggests that the system of checks and balances that should underpin good governance in universities cannot function, resulting not just in managerial predation but in excessive risk taking. In recent years UK HE has witnessed a substantive shift in power towards those who revel in the managerialist paradigm.

There has been a relative dearth of literature on university senior management leadership (Perry and Miller, 2017). However, that which has been published has tended to be unequivocal in representing university management as sociopathic leaders befuddled by a caustic combination of narcissism, psychopathy and Machiavellianism (Ibid). Craig et al. (2014) characterise university senior management regimes as supporting courts of conformers and colluders who are selfish, ambitious and openly supportive of toxic tyrants where universities, bedevilled by audit culture, are characterised as psychotic. Smyth (2017) offers a different negative characterization and nomenclature for senior university managers which he describes as 'zombie leadership', a direct outcome of the application of neoliberal ideology to the operation of UK HE (Smyth 2017).

According to Halffman and Radder (2015), the university has been occupied by a 'mercenary army of professional administrators' (165) who 
brush aside dissent as the inevitable side effect of progress. They suggest that, inherent in the indicator fetishism characterising $\mathrm{HE}$, is a fundamental notion that if people are not constantly threatened then they do not do enough. Permanent competition under the pretext of quality is, in this instance, a manifestation of an organisational mistrust besetting a managerial university that cannot judge the intangible notion of 'excellence' but believe in it nonetheless (Ibid 170).

There has been a fundamental shift in the past two decades in terms of who governs and runs universities. A decline across institutions in terms of democratic input and representation regarding university governance has been couple to a shift from management by groups of rotated academics to management by permanent managers (MacFarlane 2007) whereby this move from a collegial to a bureaucratic and hierarchical managerial culture (Rustin, 2016) has resulted in weakened positions for most staff in HE decision making. Holmwood et al (2016) concur with the loss of collective influence of academic staff over the direction of UK universities with academics and students now party to a hierarchical authority which is as secretive and arbitrary as it is ruthless (Gill, 2009).

Gill (ibid) notes that the culture of time charts, benchmarks, league tables and vision statements has been embedded in the increasingly dominant Taylorist models of academic production and assembly to the extent that, according to Halffman and Radder (2017, p896), what is at stake is the 'very notion of knowledge itself'. Lynch and Ivancheva (2015) suggest that the HE elite can, and regularly does, limit academic freedom by under-resourcing subjects for teaching and research, disallowing particular disciplines and fields of scholarly engagement and/or punishing dissent.

We can see increasingly depoliticised forms of critical thinking that have been integrated into university curricula aimed toward the entrepreneurial student (Ridley 2017; Murphy 2017) or what Bal et al (2014) call the 'entrepreneurial missteps of the modern university'. Newly hired lecturers are now under more pressure to fundraise for research, engage in teaching, supervision and administration with lowered salaries and increased contractual insecurity (Lynch and Ivancheva, 2015) and a culture of silence 
makes invisible the growing experience of precariousness, pressure and exhaustion (Berg et al. 2016).

\section{A statactivist response to the Toxic University}

Recent writings on statistical activism (often truncated to statactivism) in France and more distant liberation psychology from Latin America have provided an impulse for the research presented her. Montero and Sonn (2009, p2) discuss the need to produce a science which is constructed by praxis which they define as 'practice that produces knowledge and knowledge that turns into action'. Jiminez-Dominguez (2009) points to the value of Ignacio Martin-Baro's effective use of surveys as de-ideologisation tools against the military dictatorship in El Salvador in the 1980s. Martin-Baro believed that such tools could be mobilised to give voice to dissent. For Martin-Baro, neopositivist methods could be very useful once separated from their epistemological assumptions.

Samuel (2014) suggests that statistics can be used as a weapon to allow and resist coercion. While the quantitative data generated from HE audit practices are problematic, Samuel (2014) notes that practices of quantifying people's experiences can also help to reveal injustice. In such an outlook, calculative infrastructures can be organised to make surfaces or planes for action and resistance (Lury and Gross, 2014). Statactivism has been articulated as a militant use of figures (Baudot, 2014) whereby previous representations of reality can be challenged and contested (Bruno et al 2014). And although statistics, and the metrics through which they are produced, have long been associated with the regressive social accounting practices of the neoliberal state (Bruno et al 2014), forms of collective action that use numbers, measurements, and indicators as means of denunciation and criticism allow the capacity of previous indicators to be brought into doubt (Lury and Gross, 2014).

Such a statactivist approach might hold value in the UK HE context by extending the public gaze beyond the narrow metrics of HE whose ideological and conceptual limitations leave them heaving helplessly under the strain of representing a complex and contested public education sector. This project 
seeks to build on the central premises of statactivist approaches to knowledge development and activism in order to address what Lynch and Ivancheva (2015) describe as the failure of academics as individuals, and universities as corporate bodies, to challenge the spread of market values and new managerialism in HE. That is, to take Lynch and Ivancheva (2015) up on their challenge to publicly name the ways in which organisational strangulation and the lack of resourcing of teaching and research can, and are, distorting academic ideals, to reawaken old but much-needed conversations about what universities should be for (Savigny, 2013).

Ingold (2017) said that HE in the UK is beset on all sides by closed and self-righteous fundamentalisms, be they religious, political or economic. As such, academics cannot wait for university leaders to rise to a challenge they don't recognise. This project seeks to address this dilemma by developing a different way of thinking about accountability that restores trust and autonomy through alternative forms of measuring what is happening in UK HE (Craig et al 2014). Burton and Gomez Ordonez lament the way that 'the understanding of our reality ends up mediated by what schemata designed in other worlds can capture' (2009: 349). The UK HE Senior Management Survey (SMS) represents the first nationwide attempt to understand the realities of UK HE through schemata designed within the sector.

\section{SMS survey rationale, method, sample}

A group of lecturers in the UK started this action research project to explore the direction of HE management and evaluate different accountability measures. Despite the increasing visibility of the National Student Survey (NSS) $)^{5}$, there is much that students don't know about the many factors that set the context for the experiences that they have. We launched the UK HE Senior Management Survey (SMS) as a tool for academic staff around the UK

\footnotetext{
5 The NSS is an annual survey of final year UK HE undergraduates. Commissioned by the Office for Students on behalf of the UK university funding and regulatory bodies, the survey is administered by Ipsos MORI, a private polling company. See the NSS website at https://www.thestudentsurvey.com/ for further information regarding the survey and questions used.
} 
to assess, reflect on and comment on the practices of their senior managers. The survey sought to move the gaze from the narrow metrics of staff performance to the senior management teams who set the conditions through which staff performance becomes possible. In so doing it aimed to ask questions of the current trajectory of HE in the UK and to broaden debate about what universities should and could be for our students.

The survey mirrors the NSS process and was designed to produce a national league table of senior management teams (reproduced below). The project was granted ethical approval through the standard ethical approval process at the University of Brighton. The online survey, hosted at https://smsproject.wordpress.com/about/, consisted of 30 questions (see appendix 1) using Likert scales (strongly agree to strongly disagree) mirroring the NSS focus on satisfaction, whilst also including a series of measures to assess:

-senior management impact on students

-senior management performance

-work pressure and wellbeing

-treatment of staff

The questions were developed by a team of social scientists from around the UK and distributed online via:

- a targeted UCU email to all members

- UCU contacts in every university

- The Times Higher Education website ${ }^{6}$

5888 academic staff from across the UK completed the survey, which ran between January and May 2017. The survey is necessarily self-selecting (like the NSS). However, we have sought to recruit as widely as possible and have in some cases managed to achieve substantial numbers of staff in individual institutions. We included universities in the final results if we had a minimum of 25 academic staff who took part; from this 78 universities were included in the final analysis and construction of the league table. In practice most universities had considerably more respondents than this and some

${ }^{6}$ THE also reported on the initial findings of the SMS in October 2017 at https://www.timeshighereducation.com/news/survey-results-confirm-ukuniversity-staffs-deep-dissatisfaction 
universities had several hundred staff participating. We hope that, with further support with future iterations of the survey, we will achieve much higher response rates which will allow us to include all UK universities.

Psychometric analysis of the scales used for the tables show strong internal consistency, lending credence to the combined measures. All subscales had a Cronbach's alpha of .75 or above indicating acceptable to good internal consistency (see Appendix 2).

\section{Results}

The survey responses were used in two ways. Firstly, a league table of senior management teams was compiled from the quantitative data? Secondly, the 2,400 qualitative 'write in' comments that were collected were analysed using thematic analysis (Braun and Clarke 2006); seven major themes emerged from this process. The seven major themes were: the dominance and brutality of metrics; excessive workload; governance, accountability and HE 'fantasy football'; perpetual change and the loss of institutional memory; vanity projects; the silenced academic; and work as a mental health hazard. As highlighted in the literature presented, the dominance of metrics, and excessive workload have been covered in existent literature, therefore this paper will focus on the five themes that to date have received little attention. Firstly however, we shall present the quantitative league tables to give an account of the extent of discontent amongst staff in UK HE institutions.

\section{Quantitative results: the league table}

Mean satisfaction across the sector is $10.54 \%$ of university staff satisfied with their senior management. The highest institution scored $36.6 \%$ and the lowest $0 \%$.

\begin{tabular}{|l|l|l|}
\hline Position & University & $\begin{array}{l}\text { Percentage of staff satisfied with how } \\
\text { their university is being managed }\end{array}$ \\
\hline
\end{tabular}

\footnotetext{
7 The quantitative data was initially compiled into four subscales: staff dignity, senior management impact on students, senior management performance, wellbeing and work pressure.
} 


\begin{tabular}{|c|c|c|}
\hline 1 & University of Oxford & $36.60 \%$ \\
\hline 2 & Anglia Ruskin University & $35.00 \%$ \\
\hline 3 & Durham University & $31.10 \%$ \\
\hline 4 & The University of York & $26.20 \%$ \\
\hline 5 & University of Strathclyde & $25.50 \%$ \\
\hline 6 & $\begin{array}{l}\text { Manchester Metropolitan } \\
\text { University }\end{array}$ & $25.00 \%$ \\
\hline 7 & $\begin{array}{l}\text { Goldsmiths, University of } \\
\text { London }\end{array}$ & $24.30 \%$ \\
\hline 8 & University of Bath & $23.10 \%$ \\
\hline 9 & The University of Warwick & $23.00 \%$ \\
\hline 10 & Bath Spa University & $21.20 \%$ \\
\hline 11 & Loughborough University & $20.00 \%$ \\
\hline 12 & Nottingham Trent University & $19.50 \%$ \\
\hline 13 & Leeds Beckett University & $19.40 \%$ \\
\hline 14 & University of Exeter & $19.20 \%$ \\
\hline 15 & $\begin{array}{l}\text { University of Wales Trinity } \\
\text { Saint David }\end{array}$ & $16.00 \%$ \\
\hline 16 & Newcastle University & $15.40 \%$ \\
\hline 17 & The University of Edinburgh & $14.70 \%$ \\
\hline 18 & Aberystwyth & $13.50 \%$ \\
\hline 19 & $\begin{array}{l}\text { London South Bank } \\
\text { University }\end{array}$ & $13.40 \%$ \\
\hline 20 & Plymouth University & $13.30 \%$ \\
\hline 21 & $\begin{array}{l}\text { St Mary's University, } \\
\text { Twickenham }\end{array}$ & $13.20 \%$ \\
\hline 22 & University of Portsmouth & $13.20 \%$ \\
\hline 23 & University of Huddersfield & $12.90 \%$ \\
\hline 24 & University of Leeds & $12.50 \%$ \\
\hline 25 & $\begin{array}{l}\text { University of Central } \\
\text { Lancashire }\end{array}$ & $12.00 \%$ \\
\hline 26 & $\begin{array}{l}\text { University of } \\
\text { Wolverhampton }\end{array}$ & $11.90 \%$ \\
\hline 27 & University of Bristol & $11.50 \%$ \\
\hline 28 & University of Essex & $11.10 \%$ \\
\hline 29 & University of Roehampton & $11.00 \%$ \\
\hline 30 & The University of Sheffield & $10.70 \%$ \\
\hline 31 & $\begin{array}{l}\text { University of the West of } \\
\text { England }\end{array}$ & $10.40 \%$ \\
\hline 32 & $\begin{array}{l}\text { Liverpool John Moores } \\
\text { University }\end{array}$ & $10.30 \%$ \\
\hline 33 & University of Liverpool & $10.20 \%$ \\
\hline 34 & Sheffield Hallam University & $9.80 \%$ \\
\hline 35 & Bournemouth University & $9.40 \%$ \\
\hline 36 & University of Greenwich & $9.10 \%$ \\
\hline 37 & University of Cumbria & $9.00 \%$ \\
\hline 38 & University of Glasgow & $8.30 \%$ \\
\hline 39 & Ulster University & $8.10 \%$ \\
\hline
\end{tabular}




\begin{tabular}{|c|c|c|}
\hline 40 & SOAS, University of London & $8.00 \%$ \\
\hline 41 & University of Bradford & $8.00 \%$ \\
\hline 42 & University of Salford & $8.00 \%$ \\
\hline 43 & University of East Anglia & $7.90 \%$ \\
\hline 44 & Cardiff University & $7.70 \%$ \\
\hline 45 & University of Kent & $6.90 \%$ \\
\hline 46 & Heriot-Watt University & $6.70 \%$ \\
\hline 47 & $\begin{array}{l}\text { Southampton Solent } \\
\text { University }\end{array}$ & $6.60 \%$ \\
\hline 48 & Teesside University & $6.50 \%$ \\
\hline 49 & Oxford Brookes University & $6.10 \%$ \\
\hline 50 & University of Bedfordshire & $6.00 \%$ \\
\hline 51 & University of South Wales & $5.90 \%$ \\
\hline 52 & $\begin{array}{l}\text { The University of } \\
\text { Nottingham }\end{array}$ & $5.80 \%$ \\
\hline 53 & University of Southampton & $5.80 \%$ \\
\hline 54 & University of Sussex & $5.80 \%$ \\
\hline 55 & King's College London & $5.70 \%$ \\
\hline 56 & Northumbria University & $5.40 \%$ \\
\hline 57 & $\begin{array}{l}\text { The University of } \\
\text { Manchester }\end{array}$ & $5.30 \%$ \\
\hline 58 & University of Reading & $5.20 \%$ \\
\hline 59 & University College London & $5.10 \%$ \\
\hline 60 & University of Leicester & $5.10 \%$ \\
\hline 61 & Leeds Trinity University & $5.00 \%$ \\
\hline 62 & University of Brighton & $4.80 \%$ \\
\hline 63 & City University London & $4.70 \%$ \\
\hline 64 & University of Birmingham & $4.50 \%$ \\
\hline 65 & Swansea University & $3.80 \%$ \\
\hline 66 & University of Hertfordshire & $3.80 \%$ \\
\hline 67 & University of Aberdeen & $3.60 \%$ \\
\hline 68 & Birmingham City University & $3.30 \%$ \\
\hline 69 & De Montfort University & $3.10 \%$ \\
\hline 70 & Coventry University & $2.40 \%$ \\
\hline 71 & Kingston University & $2.30 \%$ \\
\hline 72 & University of Surrey & $2.20 \%$ \\
\hline 73 & $\begin{array}{l}\text { London Metropolitan } \\
\text { University }\end{array}$ & $1.70 \%$ \\
\hline 74 & Open University & $1.70 \%$ \\
\hline 75 & Queen's University Belfast & $1.50 \%$ \\
\hline 76 & The University of Hull & $0 \%$ \\
\hline 77 & University of Chester & $0 \%$ \\
\hline 78 & University of Westminster & $0 \%$ \\
\hline
\end{tabular}


Perhaps the most striking feature of the league table is that three institutions scored a flat $0 \%$ satisfaction rating. It would be useful if we could identify some shared characteristics of these institutions, but it is difficult to see any. Indeed, it is difficult to identify any trends in the league table in terms of geographic location, membership of the Russell Group or even general 'status' of universities. There is no pattern of, for example, more researchintensive universities appearing at the top or the bottom of the league table, nor metropolitan universities scoring higher, or lower, than provincial universities. Post-92 institutions fare no better or worse than 'old' universities. The only conclusion that we can draw is that the competence of senior managers is distributed randomly across the sector, and staff in any particular institution may simply be lucky or otherwise to have a good management team or a poor one. Judging by these results UK HE staff are more likely than not to encounter a poor senior management team.

\section{Findings}

\section{Governance, accountability and HE 'fantasy football'}

Throughout the corpus of data staff commented at length on what they felt was an injustice in terms of accountability in HE institutions. As the following participant commented:

We hold students accountable (through marking and attendance monitoring), students hold us accountable (through teaching evaluations and NSS), senior management holds us accountable. Why do we not get to evaluate senior management in the same way students get to evaluate us, and why can't these necessary metrics carry at least some weight?

Here this participant understands their experience of the current situation in HE institutions through the broad concept of accountability as a process through which individuals (both staff and students) are held responsible for their actions through notions of answerability and enforceability (Gaventa and McGee, 2013), in this case the NSS, teaching evaluations, attendance 
monitoring and marking. Interestingly however, rather than being resistant and critical of the metric culture (Beer, 2016, Smyth 2017) this participant calls out the inequity of a metric surveillance system that overlooks senior management. The lack of evaluation and accountability of the senior management is reminiscent of Holmwood et al's (2016) assertion that senior management teams are self-selecting and self-governing boards with unlimited power, and the self-governing characteristics of such boards result in the chain of accountability ending with them.

This dichotomy between staff and senior management, whereby staff are subjected to an increase in accountability and performance measurements, whilst senior management teams are perceived to be accountable to fewer metrics and layers of accountability is central to the following participant's understanding:

The University sector is not in good shape and senior management is never held accountable for this. Universities are meant to be places of learning where knowledge claims based on evidence are subject to testing and critique. However, the performance regimes in place in universities actually reduce the quality of teaching and research - that these systems are still clung to shows management to be a faith rather than evidence-based enterprise.

In the above extract the participant draws on the notion of 'faith' to suggest that lack of evidence-based enterprise and decision making by senior management at HE institutions. Explicit within this understanding is the sense that a system of evidence, checks, critique and ultimately accountability are no longer present in the functioning of decision making at HE institutions, despite being central to the teaching, learning and knowledge production at universities being built on these principles. Thus Ridley's (2017) suggestion that managerial predation and excessive risk taking are a result of the lack of good governance underpinned by a system of accountability seems pertinent within our participants understandings. Further, it is not just the lack of accountability of senior management that is resulting in the sector not being 
'in good shape' but also this participant understands the 'performance regimes' enforced on staff as a central cause of a reduction in the quality of staff teaching and research, a position echoing Gulbrandsen's (2008) argument that 'accountability recipes' are often counterproductive and result in a drop in standards.

Whilst the above could be understood as the active dismissal of accountability in senior management regimes via the self-selecting and self-governing structures in place at the top of universities, the following extracts highlight how the lack of accountability and poor management tactics might be more a result of a lack of understanding. For example:

At heart the problem is one of governance. Academic staff ultimately do not run the university. It is run by a small group of senior administrators with little idea about running a university. This leads to a lot of "initiatives" that detract from the day job of teaching, revising curricula, and doing research. "Initiatives" like a curriculum refresh are more about box ticking and buzzwords than any serious review of curriculum.

University managers are playing fantasy football with the institution: they know nothing about how it actually works and spend their time obsessing about data that is poorly collected and badly interpreted.

The senior managers I am sure work very hard in ways they perceive to generally be in the best interests of employees and the institution. I would not want their job. But I believe they ought to know more about what they are purporting to manage, and not rely on performance indicators and the quasi-anonymous process of cascading down information. They might manage, but don't lead. As a consequence, they assume their right to lead, rather than earning it.

Here we see accounts of the decline in democratic input and representation of staff in university governance systems (MacFarlane 2007). Throughout these 
accounts accountability for poor decision making is understood through the construction of a void between the knowledge and experience of senior management teams, and 'what they are purporting to manage'. Rather than being academic staff that have worked their way up the chain of command and earnt a right to lead, 'senior administrators' are 'playing fantasy football' with universities. The shift from a collegial to a bureaucratic and hierarchical managerial culture (Rustin, 2016) results in academic staff no longer collectively influencing decision making (Holmwood et al, 2016): rather, permanent managers rely on poor data and 'initiatives' to enforce a hierarchical authority (Gill, 2009) through a vocabulary of knowledge that legitimises managerial power (Craig et al 2014).

\section{Perpetual change and the loss of institutional memory}

Linked to the disconnect between senior managers and university staff (Barnett 2003; Collini 2012; Docherty 2015) was a persistent sense that a lack of understanding of what research and teaching in HE entails coupled with the desire to make the university 'better' results in constant change and uncertainty. As the following participants state:

We have had a re-organisation (a very expensive one), which effectively separates the teaching and research functions, as well as academic and non-academic functions. It means that no-one is looking to see how wellbalanced these are at an individual level.

Frankly the context of constant rudderless change and endlessly growing bureaucracy in HE means that they end up exposing us to a process of continuous revolution which erodes staff well-being, rarely benefits students' learning, and undermines grassroots creativity.

Change, uncertainty and restructuring are central to the participants' understanding and are certainly not seen as something positive throughout our data. Here we see 're-organisation' and 'rudderless change' presented as the objects of staff dissatisfaction and poor outcomes for students. Indeed, these participants understand such change regimes in a similar light to the 
accounts in the section above highlighting the lack of understanding of what it is to work on the frontline of HE in the UK by senior management. Thus we see accounts that present change and re-organisation as vehicles for the deep and arguably widening divisions between university staff and their senior management teams (e.g. Nash, 2019). This is rather succinctly expressed by the following participant:

Senior management needs to listen to 'the people on the ground' in order to understand the impact of the changes that they make.

Throughout our corpus of data it was clear that academic staff could see local changes linked to national changes imposed by the government, the change in fee structure being one of the most prominent. For example:

Reorganisation has been clumsy, heavy handed and officious. I feel less a lecturer than a shoe-fitter, such is the overwhelming rush to make students customers. I am sick of the phrase 'the student experience'. It is demoralising, this endless and toxic top-down micromanagement. The university is in the dark ages. It is a systemically mean spirited place, kept afloat by those dedicated admin and teaching staff who are conscientious.

In this extract we see the implicit reference to the change in student fees and the marketization of HE represented through reference to 'student customers' and 'the student experience' (Nixon, Scullion, and Hearn, 2018). Thus, there is recognition that local changes are part of a broader change agenda in UK HE yet the apparent 'clumsy, heavy handed and officious' nature of how local changes are implemented and handled becomes the object for staff dissatisfaction and demoralisation. Such an understanding once again constructs and reinforces the division between 'those dedicated admin and teaching staff' and the 'toxic top-down micro-management' practices of senior management teams (Barnett 2003; Collini 2012; Docherty 2015). 
Such examples of the negative impact of change featured throughout our data and was often understood in terms of staffing cuts implemented under the guise of 're-organisation', resulting in considerable increases in workloads for the staff that remain, and also as a loss of institutional identity or 'institutional memory' due to the departure of senior and long standing members of departments/institutions and the broader McDonaldization of HE in the UK (Garland, 2019). These themes are clearly expressed in the following comments:

Since a new senior manager was appointed in my department, a number of significant changes to my established working patterns have been imposed on me. The consultation process during these changes has been very limited, i.e. my job specification was changed without any consultation with me, and an increase in the number of contact teaching hours of more than $50 \%$ has been imposed.

The department I work in has seen most of the senior teaching and research staff, including all but one professor, leave by taking early retirement packages. This means that cheaper and less experienced hourly-paid and part-time staff are bearing greater and greater responsibilities for teaching and curriculum development. We have lost our 'institutional memory'.

\section{Vanity projects}

Linked to the broader changes in the culture of UK HE senior management teams was an understanding in which senior managers, and Vice Chancellors more specifically, were misusing funds to embark on various capital projects, or as some commented 'vanity projects'. As the following notes:

My view is that senior management at many $\mathrm{HE}$ institutions pursue a macho agenda of expansion for expansion's sake, involving huge expenditure on buildings and other signifiers of status, and pay for much of it by exploiting the overseas student market. 
In this extract the observation that senior management teams 'pursue a macho agenda' not for the benefit of staff and students but for 'signifiers of status' is similar to Perry and Miller's (2017) representation of university senior managers as sociopathic leaders befuddled by a combination of narcissism, psychopathy and Machiavellianism. Indeed, through the pursuit of 'expansion for expansion's sake' this participant understands the actions of their senior managers as a selfish and ambitious pursuit (see also Craig et al., 2014) which 'exploits' the recent move to international student recruitment across many UK HE institutions. Such a pursuit can be likened to the 'macho' agenda of high-class car marketing whereby fast cars are presented as identity symbols through notions of hegemonic masculinity (Hirschman, 2016). In similar vein, the following participant observes exploitation of the income generated by student fees to engage on capital projects. They comment:

It is disgraceful that university management 'top slice' the money young people pay for their education to spend on their own vanity projects.

In addition to the misuse of student fees to embark on such projects, other participants noted that the direct fall out of over ambitious 'vanity projects' was a lack of funding for more basic aspects of university functioning. For example, as one participant suggests:

Senior Management at my university is appalling. In order to support a vanity project at my university staff are put under unbearable pressure. SM are driving staff to resign, take voluntary severance, or seek other posts because there is no support for research, or to deliver good quality teaching.

Here a direct link of causality is offered up between senior management vanity projects and 'no support for research, or to deliver good quality teaching'. This appears to resonate with some of our earlier analysis which highlighted how the 'student as consumer' has shaped decision making in HE institutions over recent years. In this sense, the capital projects can be understood through the desire for the 'student experience' to be realised 
through experiences with space which represents something akin to purchasing the latest Apple Mac in an official Apple store whereby the consumer experience is increasingly sanitised, predictable and McDonaldized (Manolia, Winsor and Kelley, 2015). The result of this 'consumer experience' is a workforce facing 'unbearable pressure' resulting in an inability to deliver 'good quality' teaching and research, arguably the two elements central to the work of universities (and indeed the national REF and TEF assessments). Such expansion strategies were understood as overwhelmingly negative across the data set and once again highlight the perceived void between academic staff and senior management teams, as the following highlight:

The management is currently obsessed with spending money on new buildings; this is soaking up huge amounts of the University's budget on flashy buildings that are often unfit for purpose.

Raising large amounts of money to build more posh buildings but cutting back on staff appointments to pay the additional costs involved. I no longer have any confidence in our senior team. Buildings and vanity projects are all they believe in.

\section{The silenced academic}

Some have highlighted the failure of the academic community to embrace its freedom and fight back at the types of oppressive structures highlighted in the above analysis (Halffman and Radder, 2015). Our data shows that the reality of speaking out is somewhat different from the idealised version of freedom and creative expression in Universities (Wallerstein, 2006). As the following participant comments:

Supposed increases in transparency and consultation by senior managers are undermined by their deliberate increase in feelings of job insecurity, such that staff no longer provide info on consultations for fear of retribution. 
In this extract it is clear that the nationwide situation of precarious and insecure contracts facilitates a silencing of academic freedom. Whilst the notion of a 'community of scholars' is still widely held in UK HE (Docherty 2015: 23), in this account, that community of scholars no longer has the ability to exercise its collective voice to challenge decisions through the 'transparency' and 'consultation' mechanisms offered by senior managers. Collective voice is systemically deconstructed through the imposition of targets, performance criteria, precarity and homogenised systems for assessing research and teaching performance (Edmond, 2017). Fear of individual retribution functions to silence the contemporary academic from challenging policy and strategy within HE settings and can be understood in a similar light to the strategy Margret Thatcher's government adopted in aggressively 'taming' the trade unions in the 1970/80's (Hanson, 2016).

Whilst the above extract highlights the subtle ways in which staff silencing occurs through the individualisation of the UK HE sector via a range of strategies including individual targets and precarious employment, our data also offered many examples of more blatant and explicit silencing practices. For example:

Increasingly an environment where disagreement is not tolerated, where policies that we don't think are wise can't be argued against, and autocratic management designed to please the senior executive and not help or protect staff is preferred. Members of staff who are awkward and have strong views that aren't welcome are in danger of being made 'redundant' when they are not redundant (as has happened in one case that I know of).

Here we see an account in which senior managers are argued to be far more active in the silencing of staff. In this account 'disagreement is not tolerated' and to silence disagreement employment security (or lack of) is used as a tool to control dissenting opinions. Such an account echo's the concerns of Lynch and Ivancheva (2015) who suggest that the HE elite can, and regularly does, limit academic freedom by sanctioning dissent. Thus, it appears that such 
hardline managerialism systematically deconstructs the space through which professional autonomy and freedom of expression, two things argued to be symbolic of universities (Docherty, 2015), are exercised (Olssen and Peters, 2005). Therefore, far from the mythical story of the university promoting creativity in a community of scholars (Barnett 2003; Collini 2012; Smyth 2017), senior management at universities appear to be enforcing a system more akin to a dictatorship enforcing compliance rather than critique, as the following participant articulately states:

People keep disappearing in a most macabre way. It is like living through Stalin's purges. I think this university is going to have a severe problem recruiting given the way it treats its existing faculty.

\section{Work as a mental health hazard}

Our final theme - work as a mental health hazard - is perhaps the most troubling. Implicated here are the four themes that precede it, accountability, change, capital projects and the resulting silencing of the academic, which impact on staff wellbeing and mental health. For example, as one participant highlights:

Over the past couple of years my anxiety levels have reached critical to the extent that I literally find it hard to breathe. I often wake in the early hours and can't go back to sleep because of having to make notes about things I've forgotten to do at work. New management at faculty level since September uses crude face to face teaching hours as a measure of workload and tells me mine is too low. It's Saturday morning and I'm sitting in front of a computer doing work.

In this extract the mental health impacts faced by academics at UK HE institutions are laid bare. Far from the 'myth' of the university (e.g. Wallerstein, 2006) highlighted earlier in which academic freedom, knowledge advancement and generally a progressive environment were seen to symbolise HE institutions, it appears academics are faced with something in stark contrast to these representations; a toxic environment which often 
manifests through characteristics of generalised anxiety disorder (e.g. struggling to sleep and breathe). Linked to a 'new management' regime and implicitly associated with the restructuring of workloads, this participant falls foul of the problematic distribution of resources highlighted earlier in this analysis and the difficultly to 'switch off' from work due to modern working contexts and technologies (Sonnentag and Bayer, 2005).

In addition to the allocation of resources and change at work resulting in negative wellbeing impacts for staff, others highlighted how this links to the ever-increasing silencing of academics mentioned above, as the following notes:

Not surprising then, the number of staff with mental health problems in my department (but also within the university at large) and colleagues expressing signs of exhaustion has soared in recent years. All this of course is nothing to be discussed openly as it would bring the department or university into disrepute.

Here then, not only are staff experiencing mental health difficulties faced with the general negative stigma surrounding mental health disclosure in the work place (e.g. Krupa et al., 2009) but they appear to be experiencing further silencing due to fears of bringing 'the department or university into disrepute', presumably something which senior managers are keen to avoid.

Whilst these examples could be seen as unfortunate and unplanned outcomes of broader processes of change and adaptation in a shifting $\mathrm{HE}$ landscape, prominent throughout the data set were examples of more preplanned, potentially premeditated examples of senior management having a negative impact on staff wellbeing and mental health. The two following comments provide clear examples:

I have seen senior management break junior staff down to serious psychological illnesses with their extended probation times and shifting goals. I am only glad that I joined before that came in- now, I am just 
waiting for my child to change schools and I will leave the country. Nothing is worth this stress. This University is inhumane.

Senior management seem distant and uncaring. They have created a disillusioned and despondent workforce.

In both of these extracts a far more cynical account is offered up in terms of the relationship between senior management and staff. Drawing on tropes of 'inhumane', 'distant' and 'uncaring', senior management are presented as a group of individuals who are not passively inflicting negative staff wellbeing impacts via broader institutional change and uncertainly. Rather in these accounts they are presented as a group of individuals who 'break junior staff down to serious psychological illness' and create a 'disillusioned and despondent workforce' through enforcing a suffocating array of audit assemblages (Spooner, 2017), which are largely unachievable due to the 'shifting goals'. Thus academic staff and particularly newly hired lecturers on 'extended probation times' are under excessive and unreasonable pressure to achieve more with increased contractual insecurity (Lynch and Ivancheva, 2015). The culture of silence highlighted above appears to hide the extent of 'stress', 'psychological illness', 'disillusionment' and precariousness, pressure and exhaustion amongst university staff (Berg et al. 2016).

The health and wellbeing impact of such experiences is summarised in the following extract which highlights the negativity and helplessness of the HE workforce:

I have a long-term health condition and working here has made my problems significantly worse. Every day is a painful misery due to this, and I don't know how much longer I can take it. Increasingly I feel that the last 15 years of my life have been a waste, and that academia in this country is irreparably broken. 


\section{Summary and conclusion}

Fine (2018) argues that there is an increasing need to interrogate how evidence has been deployed to legitimate the hollowing out and colonisation of public institutions. As our data suggests, this is especially crucial for a UK $\mathrm{HE}$ sector characterised as being eaten alive by corporate logic and relentless metrics of punitive accountability. However, when surveying the academic literature on the demise of the public university it is difficult not to be struck by the surfeit of progressive injunctions for change resting on a deficit of concrete plans to action these injunctions for change.

Halffman and Radder (2015) and Martell (2017) suggest that university colonisation is a success because academics have cooperated en masse whereby critical social scientists write 'sharp papers' against the travails of managerialism and metrics but then meekly conform to its introduction in their own universities, hoping and praying they sit at the bottom of the list when 'the weakest sheep are sent to the slaughter' (p. 175). Spooner (2017) concurs, noting that universities are not innocent victims but knowing accomplices in this savage and capricious managerial domination, and asks whether universities actually have the potential to disrupt these hierarchies and inequitable power structures. Martell (2017) suggests that academics are rather better at criticising the marketisation of society than resisting the marketisation of higher education, a point made in the context of the USA in Bill Readings' seminal, and prescient for the UK, The University in Ruins (1996).

Despite this, there has been no shortage of suggestions for directions of travel from the 'sharp papers' published. These include the need for the sovereignty of academic boards for financial, pedagogical and organisational issues, membership of boards to be elected by a majority of staff and for the staff on them to be actively engaged in teaching/research, and governors to be elected for 3 year terms (Holmwood et al 2016). Some suggest a need to move to accessible institutions that foster critical, creative, engaged citizenship while generating public interest research (Spooner, 2017). There 
has been the proposition that all managerial posts should consist of rotated academics, not managers, and a need to privilege community research and slow scholarship and to re-appropriate concepts of quality and accountability while exposing the nature of coercive audit culture (Spooner, 2017). Halffmann and Radder (2015) suggest the need for a public university aimed at the common good, the need to limit wasteful audit and control systems and for no more than $10 \%$ of academic time to be spent on administrative overheads. They also suggest a ban on mergers and overfunded prestige hobbyhorses and argue that all academic members should teach at least $20 \%$ and a ban on marking (Halffman and Radder, 2015).

However, despite these progressive recommendations we continue to experience a dominant culture of theoretical and practical fatalism that has largely stopped short of moving beyond sharp words in journal articles. Some commentators have noted that this fatalism is not misplaced: 'the effect of these arguments and objections on those who make and implement policies for universities has been ... all but invisible' (Collini 2012: 116). But Collini also notes that these objections have 'won the intellectual argument'. It is simply the case that those making policy are not listening to these sharp words. Given this, we need to consider other responses, other strategies.

The UK HE Senior Management Survey (SMS) represents the first nationwide attempt to understand the realities of UK HE through schemata designed within the sector. In so doing it represents an iteration of statactivism that moves beyond 'sharp words' with a metric oriented to the performance of the senior management teams who set the conditions through which staff performance becomes possible. The survey mirrors the NSS process and produced a national league table of senior management teams to intervene in the seeming decline of UK Higher Education, and hence operate as a practice of resistance of sorts.

It could be argued that our SMS league table is predictable and is only indicative of a lack of engagement and a culture of complaining on the part of academic staff. After all, reports of high levels of disquiet with university senior 
managers' performance preceded this project, and senior managers responses were to dismiss these reports. Former Vice Chancellor Sir David Watson, writing on the 'question of morale' in HE, identified this some time ago:

"There is a comforting tale that heads of higher education institutions (HEls) like to tell each other. 'Go around your university or college,' they say, 'and ask the first ten people who you meet how their morale is. The response will always be "rock-bottom." Then ask them what they are working on. The responses will be full of life, of optimism and of enthusiasm for the task in hand." (Watson 2009) However, we disagree with such dismissiveness. In the SMS our very extensive qualitative data corroborates and extends our understanding of how dramatically and rapidly universities have changed in recent years. Many of the narrative accounts we received were stark in their presentation of academic staff in very difficult, stressful, upsetting and sometimes demeaning situations And whilst it could be claimed that managers have a right to manage, and that senior managers in many universities are innovating and changing their institutions in response to external conditions changing (notably the introduction of the $£ 9,000$ tuition fees regime) we must point to the data we collected that shows considerable human health consequences both physical and mental - from these management regimes for so many university employees.

The qualitative data that the SMS collected reveals an acute situation of endemic bullying and harassment, chronic overwork, high levels of mental health problems, general health and wellbeing problems, and catastrophically high levels of demoralization and dissatisfaction across the UK HE sector. This suggests that a sector that is vitally important for the UK knowledge economy is on the edge of potential disaster. For this reason we feel that the SMS, if nothing else, is a call to action to demonstrate, and support responses to, the woeful state of management and governance in the UK HE sector. 


\section{References}

Bailey, M. and Freeman, D. (Eds.) (2011) The Assault on Universities London: Pluto Press

Bal, E., Grassiani, E. and Kirk, K. (2014). 'Neoliberal individualism in Dutch Universities.' Learning and Teaching, 7 (3), 46-72.

Ball, S. J. (2012) 'Performativity, commodification and commitment: an I-spy guide of the neoliberal university.' British Journal of Educational Studies, 60 (1), 17-28.

Barnett, R. (2003) Beyond all reason: living with ideology in the university, Buckingham: Society for Research into Higher Education and Open University Press.

Baudot, P. (2014) 'Who's counting? Institutional Autonomy and the Production of Activity Data for Disability Policy in France (2006-2014).'

Partecipazione e Conflitto, 7 (2), 294-313.

Beer, D. (2016) 'Systems of measurement have a productive power in our lives.' LSE British Politics and Policy Blog http://blogs.Ise.ac.uk/politicsandpolicy/the-productive-power-of-metrics/ (accessed 090119)

Berg, L. D., Huijbens, E. H. and Gutzon Larsen, H. (2016) ‘Producing Anxiety in the Neoliberal University.' The Canadian Geographer 60 (2) 168-80

Braun, V. and Clarke, V. (2006) 'Using thematic analysis in psychology', Qualitative Research in Psychology, 3 (2) 77-101.

Bruno, I., Didier, E., and Vitale, T. (2014) 'Statactivism: Forms of action between disclosure and affirmation.' Partecipazione e Conflitto, 7 (2) 198-220.

Burrows, R. (2012). 'Living with the H-Index? Metric Assemblages in the Contemporary Academy.' The Sociological Review, 60 (2) 355-372.

Burton, M. and Gomez Ordonez, L. H. (2009) 'Liberation psychology - another kind of critical psychology.' In: Montero, M. and Sonn, C.C. (Eds.)

Psychology of liberation: theory and applications, New York: Springer.

Collini, S. (2012) What are universities for? London: Penguin.

Craig, R., Amernic, J., and Tourish, D. (2014). 'Perverse Audit Culture and Accountability of the Modern Public University.' Financial Accountability and Management, 30 (1) 1-24.

Docherty, T. (2015) Universities at war, London: Sage.

Downs, Y. (2017) 'Neoliberalism and the value of higher education', In Rudd, T. and Goodson, I. (eds) Negotiating Neoliberalism: developing alternative visions, Rotterdam: Sense Publishers.

Edmond, N. (2017) 'Beyond 'entrepreneurialism of the self', In Rudd, T. and Goodson, I. (eds) Negotiating Neoliberalism: developing alternative visions, Rotterdam: Sense Publishers.

Espeland, W., and Sauder, M. (2007). 'Rankings and Reactivity: How Public Measures Recreate Social Worlds'. American Journal of Sociology, 113 (1) $1-40$.

Fine, M. (2018) 'Accumulation and Its Dis(sed) Contents: The Politics of Evidence in the Struggle for Public Education,' In Spooner, M. and McNinch, J. (eds) Dissident knowledge in higher education Regina: University of Regina Press.

Finn, M. (2015). 'Atmospheres of progress in a data-based school.' Cultural geographies 23 (1) 29-49 
Fotiadou, M. (2018). 'Denaturalising the discourse of competition in the graduate job market and the notion of employability: a corpus-based study of UK university websites.' Critical Discourse Studies, DOI: 10.1080/17405904.2018.1546606

Garland, C. (2019). 'The McDonaldization of Higher Education?: Notes on the UK Experience.' Fast Capitalism, 4 (1) 107-10

Gaventa, J. and McGee, R. (2013) 'The Impact of Transparency and Accountability Initiatives.' Development Policy Review, 31: s3-s28.

Gill, R. (2009). 'Breaking the silence: the hidden injuries of the neoliberal academia', In Ryan-Flood, R. and Gill, R. (eds.). Secrecy and silence in the research process: feminist reflections. London: Routledge.

Gill, R. (2014) 'Academics, Cultural Workers and Critical Labour Studies', Journal of Cultural Economy, 7 (1) 12-30.

Gulbrandsen, L. H. (2008) 'Accountability Arrangements in Non-State Standards Organizations: Instrumental Design and Imitation.' Organization 15 (4) 563-83.

Hacking, I. (2002) Historical Ontology London: Harvard University Press

Halffman, W. and Radder, $\mathrm{H}$. (2015) 'The academic manifesto: from an occupied to a public university.' Minerva, 53, 165-187.

Hanson, C. (2016). Taming the trade unions: A guide to the Thatcher government's employment reforms, 1980-90. London: Palgrave Macmillan

Hirschman, E. C. (2016). Branding masculinity: Tracing the cultural foundations of brand meaning. London: Routledge.

Holmwood, J, Hickey, T, Cohen, R, and Wallis, S. (2016). In defence of public higher education: knowledge for a successful society. Convention for Higher Education.

Ingold, T. (2017) 'How scholars at one UK institution are reclaiming their university.' Times Higher Education 21 $1^{\text {st }}$ March 2017

Jiminez-Dominguez, B. (2009) 'Ignacio Martin Baro's social psychology of liberation.' In: Montero, M. and Sonn, C.C. (Eds.) Psychology of liberation: theory and applications, New York: Springer.

Krupa, T., Kirsh, B., Cockburn, L., and Gewurtz, R. (2009). Understanding the stigma of mental illness in employment. Work, 33 (4), 413-425

Lury, C, and Gross, A. (2014) 'The downs and ups of the consumer price index in Argentina- from national statistics to big data.' Partecipazione $e$ Conflitto, 7 (2), 258-277.

Lynch, K, and Ivancheva, M. (2015) 'Academic freedom and the commercialisation of universities: a critical ethical analysis.' Ethics in Science and Environmental Politics, 15 (1), 71-85.

Macfarlane, B. (2007) The academic citizen: the virtue of service in university life, London: Routledge.

Manolis, C., Winsor, R. D., and Kelley, S. W. (2015). Service Delivery: Postmodern Perspective. In Wilson, E. and Hair, J. (Eds.) Proceedings of the 1996 Academy of Marketing Science (AMS) Annual Conference Heidelberg: Springer.

Martell, L. (2017). 'Book review: accelerating academia: The changing structure of academic time by Filip Vostal.' LSE Review of Books http://blogs.Ise.ac.uk/lsereviewofbooks/2017/08/18/book-review- 
accelerating-academia-the-changing-structure-of-academic-time-by-filipvostal/ (accessed 090119)

Montero, M, and Sonn, C. (2009) 'About liberation and psychology: an introduction.' In: Montero, M. and Sonn, C.C. (Eds.) Psychology of liberation : theory and applications, New York: Springer.

Murphy, S. (2017) Zombie university: thinking under control, London: Repeater Books.

Nash, K. (2019). 'Neo-liberalisation, universities and the values of bureaucracy'. The Sociological Review, 67 (1), 178-193.

Neary, M., and Winn, J. (2017) 'Beyond Public and Private: A Framework for Co-operative Higher Education.' Open Library of Humanities, 3 (2), 2.

Nixon, E., Scullion, R., and Hearn, R. (2018). 'Her majesty the student: marketised higher education and the narcissistic (dis) satisfactions of the student-consumer'. Studies in Higher Education, 43 (6), 927-943.

Olssen, M. and Peters, M.A. (2005) 'Neoliberalism, higher education and the knowledge economy from the free market to knowledge capitalism'. Journal of Education Policy, 20, (3), 313-345.

Perry, C. and Miller, P. (2017) 'Dysfunctional Leadership in Universities: identifying and dealing with sociopaths', in Hall, D. and Ogunmokun, G. (Eds.) Management, Leadership and Marketing of Universities and Colleges of Higher Education, Chennai: Global Publishing House International

Power, M. (2000). 'The Audit Society - Second Thoughts' International Journal of Auditing 4 (1) 111-19.

Power, M. (2015). 'How accounting begins: object formation and the accretion of infrastructure.' Accounting, organisations and society, 47, 43-55.

Readings, B. (1996) The university in ruins, London: Harvard University Press.

Ridley, D. (2017) 'Institutionalising critical pedagogy: Lessons from against and beyond the neoliberal university.' Power and Education, 9 (1), 6581.

Rudd, T. and Goodson, I. (eds) (2017) Negotiating Neoliberalism: developing alternative visions, Rotterdam: Sense Publishers.

Rustin, M. (2016) 'The neoliberal university and its alternatives.' Soundings, $63,147-170$

Samuel, B. (2014) 'Statistics and political violence: Reflections on the social conflict in 2009 in Guadeloupe,' Partecipazione e Conflitto, 7 (2), 237257.

Savigny, H. (2013) 'The (Political) Idea of a University: Political Science and Neoliberalism in English Higher Education.' European Political Science, 12 (4), 432-39.

Smyth, J. (2017) The toxic university: zombie leadership, academic rock stars and neoliberal ideology. London: Palgrave Macmillan

Sonnentag, S., and Bayer, U. V. (2005). 'Switching off mentally: predictors and consequences of psychological detachment from work during off-job time'. Journal of Occupational Health Psychology, 10 (4), 393.

Spooner, M. (2017) 'Qualitative research and global audit culture.' In: Denzin, N. K., and Lincoln, Y. S. (Eds.) The SAGE handbook of qualitative research 5th edition. Thousand Oaks; London: Sage Publications. 
Universities UK (2016) Patterns and Trends in UK Higher Education 2015. London: UUK

Wallerstein, I.M. (2006) European universalism: the rhetoric of power, New York: New Press

Watson, D. (2009) The question of morale: managing happiness and unhappiness in university life, Maidenhead: McGraw-Hill/Open University Press.

\section{Appendix 1: SMS questionnaire}

There were 30 questions in the survey; participants were invited to indication their response as one of:

Definitely agree, mostly agree, neither agree nor disagree, mostly disagree, definitely disagree, not applicable.

After completing the 30 questions participants were presented with a screen which said 'Please feel free to add any comments'.

Finally, participants were asked for their university, university role, gender identify, age, and ethnicity.

Questions:

1. My senior management provide me with the resources necessary to do the best job I can for the students

2. The way that my senior management calculate my working hours leaves me sufficient time to support students

3. My institution gives me enough time to be able to support my students' needs

4. My senior management positively impacts how I can support my students

5. I don't get enough time to prepare teaching

6 . I have sufficient time in my workload to prepare good quality student feedback

7. My senior management enables me to support students

8. NSS and/or module feedback scores are being used to encourage the best performance of staff

9. My senior management allow me freedom to pursue a research agenda that I believe is important

10. My senior managers are sympathetic to the competing pressures of REF and student support

11. The pressure I experience to bring income into my Department negatively affects my students

12. My university enables me to support my local community

13. We employ staff on zero hour contracts at my university

14. I believe my senior managers work hard

15. I believe my senior manages deserve the salaries that they are paid

16. My senior management have sold university properties/campuses in the last five years.

17. My senior managers are taking steps to reduce the number of staff on short term and insecure teaching contracts at my university

18. To the best of my knowledge, my senior management favour trying to hold down tuition fees 
19. Pressure to reach REF and other publication targets negatively affects my wellbeing

20. My senior management provides resources to support my wellbeing at work

21. My working environment is supportive

22. The physical environment in which I work is unsafe

23. My working environment has a negative impact on my wellbeing

24. I feel respected and valued by my senior management

25 . I regularly have to work evenings and/or weekends in order to fulfil my academic roles

26. My senior management supports all employees equitably

27. My senior management communicates changes effectively

28. Progression processes are transparent

29. I have access to specialised equipment, facilities and rooms when I need them

30. I am satisfied with the way my university is managed

\section{Appendix 2: Reliability}

1. The staff dignity subscale is internally consistent

\section{Reliability Statistics}

\begin{tabular}{l|l|l} 
& $\begin{array}{l}\text { Cronbach's Alpha } \\
\text { Based on Standardized } \\
\text { Cronbach's Alpha }\end{array}$ & \\
\hline .754 & Items & N of Items \\
\hline
\end{tabular}

2. The senior management impact on students subscale is internally consistent

\section{Reliability Statistics}

\begin{tabular}{l|l} 
Cronbach's Alpha & N of Items \\
\hline .834 & 9 \\
\hline
\end{tabular}

3. The senior management's performance subscale is internally consistent

\section{Reliability Statistics}

\begin{tabular}{l|l|l} 
& $\begin{array}{l}\text { Cronbach's Alpha } \\
\text { Based on Standardized } \\
\text { Cronbach's Alpha }\end{array}$ & \\
\hline .799 & Items & N of Items \\
\hline
\end{tabular}

4. The wellbeing and work pressure subscale is internally consistent 


\section{Reliability Statistics}

\begin{tabular}{l|l|l} 
Cronbach's Alpha & $\begin{array}{l}\text { Cronbach's Alpha } \\
\text { Based on Standardized } \\
\text { Items }\end{array}$ & N of Items \\
\hline .769 & .768 & 7 \\
\hline
\end{tabular}

